\title{
DESIGN SOLUTIONS FOR INSTRUMENTAL HYDROPONIC GREENHOUSES FOR RECEPTIVE PURPOSES
}

\author{
FABRIZIO CUMO ${ }^{1}$, BARBARA DE LIETO VOLLARO ${ }^{1}$, ELISA PENNACCHIA ${ }^{1}$, \\ ROSSELLA ROVERSI $^{2}$ \& VALENTINA SFORZINI ${ }^{1}$ \\ ${ }^{1}$ Department of Planning Design and Technology of Architecture, Sapienza University of Rome, Italy \\ ${ }^{2}$ Interdepartmental Centre for Territory, Building, Conservation and Environment, \\ Sapienza University of Rome, Italy
}

\begin{abstract}
The present paper deals with an innovative use of hydroponic greenhouses, in which plants grow without soil, using mineral nutrient solutions in a water solvent. The paper highlights the advantages of the hydroponic cultivation system and describes the project of a particular solar greenhouse that can be used as a space for the cultivating of vegetable species, but, thanks to its transformability features, can generate spaces assigned to different destinations: the proposed solar greenhouse can be occasionally adapted in order to become a receptive facility, exploiting an innovative system for cultivation lifting. The result is a flexible, modular and mobile architectural structure, totally reversible and energetically independent, providing support to a farming activity. Consequently, it may help even the Italian tourist industry that is increasingly based on country $\mathrm{B} \& \mathrm{~B}$ and agritourisms located in the most valuable zones that always are even national, regional or local protected areas where the construction of new traditional building is prohibited.
\end{abstract}

Keywords: hydroponic greenhouses, receptive facilities, mobile and modular structures, protected areas, soilless cultivations, mineral nutrition, climate control.

\section{INTRODUCTION}

One of the major issues that may be encountered in protected and/or constrained areas on the Italian territory is the impossibility on the part of agricultural entrepreneurs to get permission to expand their companies.

The presence of several National and/or Regional Parks does not allow for new building constructions nor for an increased cubic volume in the above-mentioned areas [1]. The only possibility granted by the current relevant legislation, is that of creating mobile and removable structures having low environmental impact [2], [3].

Among the most recent and interesting innovations in cultivation techniques, the passage from soil to soilless cultivation is to be found [4], [5]; one of the main typologies of this kind of cultivation is Hydroponics (from the Greek "Idros" water, "panos" work) (Fig. 1) [6], [7]. The term Hydroponics groups together all agricultural soilless cultivation techniques which obviate the problem of soil exhaustion issues and the excessive use of phytosanitary treatments.

At present this technique has little diffusion in Italy, involving roughly $3 \%$ of the entire surface of protected cultivations, while in North Europe it accounts for over 50\%. In spite of the advantage this technique offers, soilless cultivations are slow to take-off because of the present high initial costs of investment.

Namely, taking into consideration that transport of company products on the Italian national territory, takes place mostly through the use of heavy vehicles, mainly powered by diesel fuel, a consumption of 1 liter to cover $5 \mathrm{~km}$ has been estimated. As a consequence, an emission of $2.5 \mathrm{~kg} / \mathrm{l}$ of carbon dioxide may be estimated in the atmosphere, which could be 
avoided if the decision was made to make use of this technique, improving outdoor air quality levels and reducing climate change effects due to greenhouse gases emissions [8], [9].

\section{GREENHOUSES: DEFINITION AND FUNCTIONS}

The planning and construction of greenhouses is currently regulated by Normative UNI 13031-1/2004 "Greenhouses: planning and construction" which cites the European Standard EN 13031-1/2001 defining a Greenhouse as a: "Facility used for the cultivation and/or protection of plants and crops which exploit the transmission of solar radiation under controlled conditions to improve the growth environment, with sufficient dimensions suitable to allow people to work inside them".

The definition UNI-CEN, in its conciseness, allows for the understanding of when a structure may dhactually be defined as a Greenhouse: it defines the type of usage, describing the characteristics of coating materials, which must necessarily allow for the transmitting of solar radiation; it specifies the modalities for air-conditioning in interior environments, and how to obtain suitable working conditions through the creation of suitable environments in terms of size, space and safety.

A greenhouse is a facility for protecting crops from external weather conditions. It must be designed in such a way as to be able to directly influence the internal microclimate and biological cycle of plants (Fig. 2). For this reason, a rough calculation of the heating requirements taking into account heat loss related to coverage materials, the characteristics of the materials, the external temperature and exchange surface of the above-mentioned facility must be carried out (Figs 3-5).

A traditional greenhouse may be catalogued according to two different typologies: fixed and mobile. The main difference being the price as the mobile version is not usually heated. A greenhouse facility is generally made up of a masonry base, walls and clear coating for better filtering of light, and a framework which can be made of several materials such as: wood, iron or aluminum.

One of the fundamental aspects in the designing of greenhouses concerns the airconditioning system, involving the study of internal temperatures, relative humidity, environmental brightness and air exchange [10].

Consequently, greenhouses may be divided into cold, temperate or warm; in the first case, the temperature will range between $0^{\circ}$ and $15^{\circ} \mathrm{C}$, in the second between $10^{\circ}$ and $20^{\circ} \mathrm{C}$, in the last the average temperature is of about $22^{\circ} \mathrm{C}$ thus recreating a tropical climate. Whatever the chosen solution, though, the fundamental aspect is always relative to a perfect thermal insulation in order to avoid heat and energy dispersion (Tables 3-4).
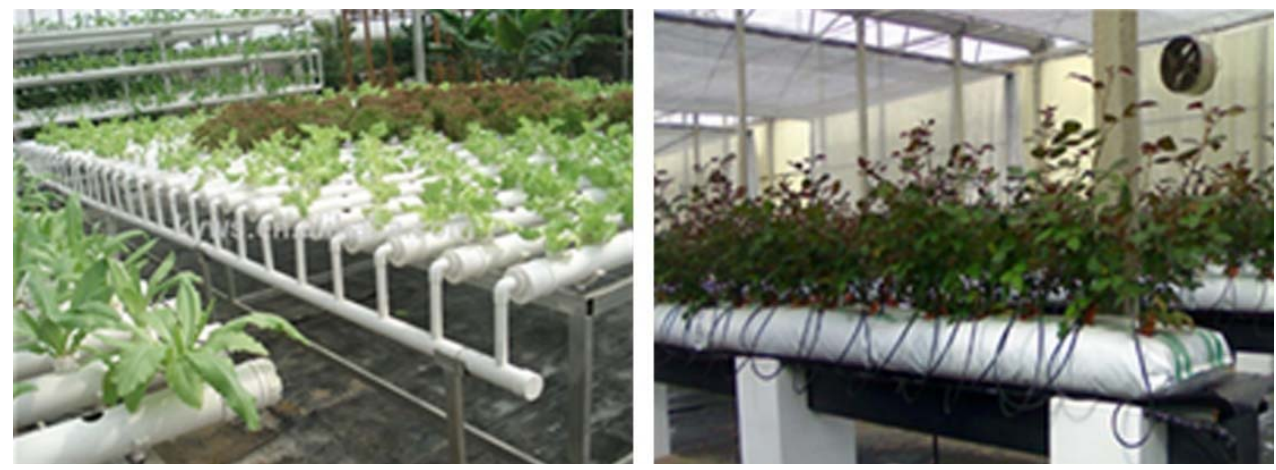

Figure 1: Hydroponic cultivation example. 


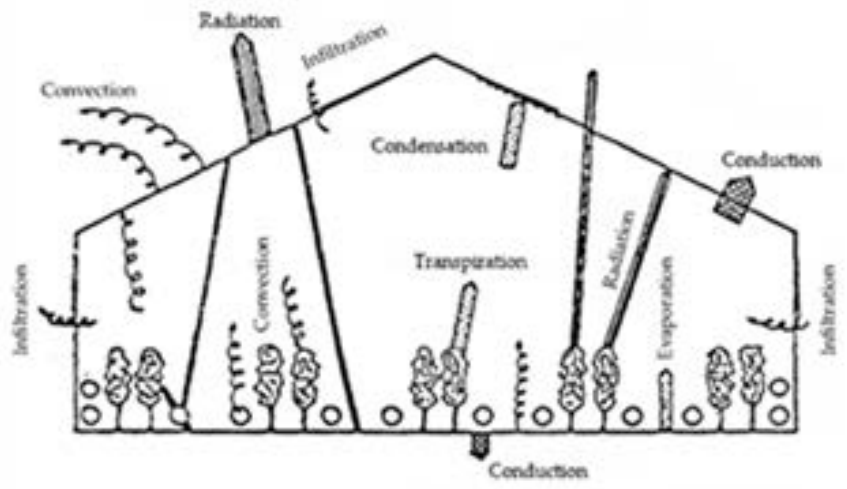

Figure 2: Greenhouse system energetic fluxes scheme.

$$
Q=A c \cdot U \cdot(\mathrm{Ti}-\mathrm{Te})(\mathrm{W})
$$

Heat supply for each greenhouse $\left(\mathrm{m}^{2}\right)$, is:

$$
\mathrm{q}=\mathrm{Ac} / \mathrm{Ag} \cdot \mathrm{U} \cdot(\mathrm{Ti}-\mathrm{Te})\left(\mathrm{W} / \mathrm{m}^{2}\right)
$$

Where:

$-\mathbf{U}=$ overall heat exchange coefficient

$-A \mathbf{c}=$ greenhouse covering $\left(\mathrm{m}^{2}\right)$

$-\mathrm{Ag}=$ cultivation area $\left(\mathrm{m}^{2}\right)$

- $\mathrm{Ti}=$ indoor optimal temperature $\left({ }^{\circ} \mathrm{C}\right)$

-Te= outdoor minimal temperature $\left({ }^{\circ} \mathrm{C}\right)$

Overall U coefficient depend from covering materials, thermal plant used, wind velocity, irrigation system, rain and meteorological conditions.

Figure 3: Thermal demand scheme (Q). 


$$
\mathbf{q i}=\mathbf{h i} \cdot(\mathrm{Ti}-\mathrm{Te})\left(\mathrm{W} / \mathrm{m}^{2}\right)
$$

Where heat exchange coefficient is:

$$
h i=(n \cdot V \cdot d \cdot C p) /(A g \cdot 3.600)\left(W / m^{2} E K\right)
$$

With:

$-\mathrm{n}=\mathrm{n} 1 \times \mathrm{c}$ exchanged air flow rate $(\mathrm{vol} / \mathrm{h})$

$-\mathrm{V}=$ air volume in greenhouse $\left(\mathrm{m}^{3}\right)$

$-\mathrm{d}=$ air density $\left(\mathrm{Kg} / \mathrm{m}^{3}\right)$

$-\mathrm{Cp}=$ air specific heat at fixed pressure $(\mathrm{J} / \mathrm{Kg} / \mathrm{K})$

Outside air leakage depends on greenhouse shape, covering material and on wind direction and velocity.

Figure 4: Thermal demand scheme (Q).

$$
\begin{aligned}
& \qquad \mathrm{qI}=\mathbf{I} \cdot \mathrm{Y} \cdot \mathrm{T}\left(\mathrm{W} / \mathrm{m}^{2}\right) \\
& \text { Where: } \\
& -\mathrm{I}=\text { solar radiation power }(\mathrm{global})\left(\mathrm{W} / \mathrm{m}^{2}\right) \\
& -\mathrm{T}=\text { transmittance of greenhouse } \\
& -\mathrm{Y}=\text { greenhouse absorption coefficient }
\end{aligned}
$$

Hot water demand is connected to greenhouse heat quantity by the formula:

$$
\mathrm{Q}=\mathrm{C} \cdot(\mathrm{T} 1-\mathrm{T} 2) \cdot \text { flow rate }(\mathrm{W})
$$

Where:

Q - heat quantity $(\mathrm{W})$

$-\mathrm{C}=$ water heat exchange coefficient $(\mathrm{J} / \mathrm{KgK})$

-T1 = inlet water temperature $(\mathrm{K})$

-T2 = outlet water temperature $(K)$

The water flow rate is:

Flow rate $=\mathrm{Q} /[\mathrm{C} \cdot(\mathrm{T} 1-\mathrm{T} 2)](\mathrm{Kg} / \mathrm{s})$

Figure 5: Incident solar radiation scheme (qI) and hot water demand.

\section{HYDROPONIC GREENHOUSES: ADVANTAGES AND DISADVANTAGES}

Already known to ancient Egyptians, their first experimental application dates back to the 1920s in California with the aim to obviate issues related to soil salinization and soil-borne pathogens. The high costs of the materials used and difficulties in the design and management of these greenhouses have made them a not widely diffused technique, scarcely carried out up to the present day. Despite the advantages offered by this technique, especially in the handling of mineral nutrition and in disease control, soil-free cultivations struggle to takeoff, both due to lack of adequate technical-professional preparation and for the higher initial investment they require. 

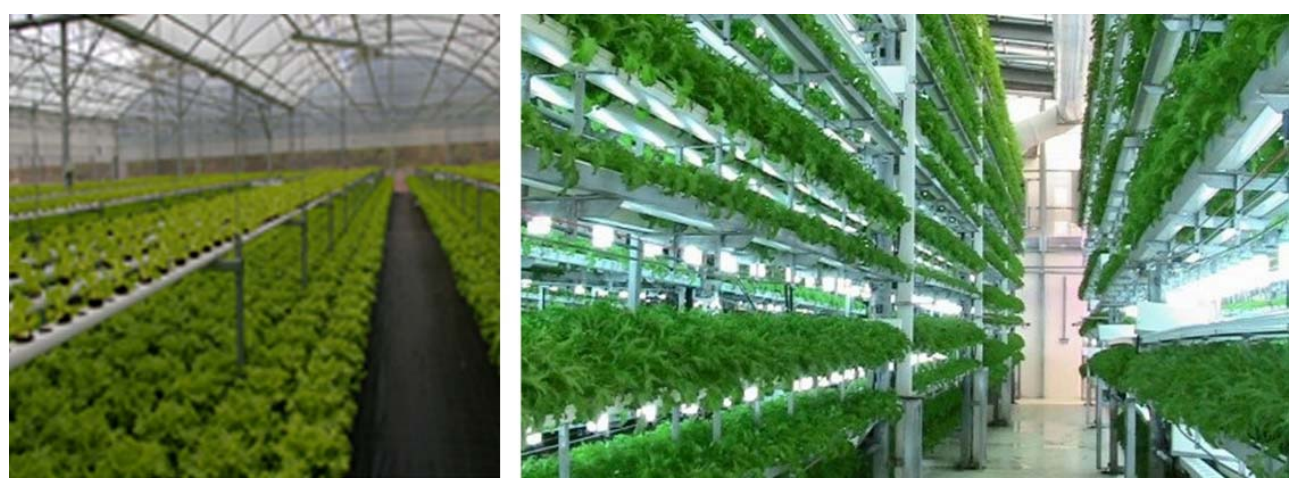

Figure 6: Hydroponic greenhouse examples.

Nonetheless interest in hydroponics on the part of farmers/entrepreneurs has increased exponentially, due to both its intrinsic advantages and the ease of transformation of these greenhouses into other temporary destinations of use, such as receptive facilities. Furthermore, this new technology allows to overcome some of the issues related to the agroindustrial sector: the ever growing competition resulting from a globalized market for products and their marketing; the need to reduce production costs; improvement in the quality of products and the lack of resources such as labour, energy and water [11] reducing environmental hazards [12], vulnerabilities [13] and risks [14] (Fig. 6).

Hydroponics is considered an eco-compatible cultivation technique as it does not involve geo-sterilizers and, in closed cycles, allows for huge reductions in the use of water and fertilizers [15] ensuring good standards of ecological sustainability [16]. This represents a further reason for approval on the part of the market considering that not only the traditional aspects, such as the flavor and taste of a product are preserved, but that greater attention is also paid to environmental and social aspects related to production.

\subsection{Hydroponic culture systems}

This Hydroponic systems can be classified according to three different methods:

- Type of substrate (substrate culture and hydro-culture)

- Mode of intake of the nutrient solution to the culture (drop irrigation and subirrigation)

- Presence of drained nutrient solution (open cycle and closed cycle)

\subsubsection{Classification according to the type of substrate}

The substrate culture is generally used for the production of ornamental vegetables and vase plants. For the first, nutrient supply is achieved through fert-irrigation, while sub-irrigation is generally used for the seconds, where vessels are placed in channels with intermittent flow of nutrient solution. Currently, the most popular growth media are peat or coconut substrates, perlite or rock wool.

The hydro-culture system combines all the techniques of cultivation in water and the N.F.T. (Nutrient Film Technique), the floating system and the aeroponic system are the most used [17], [18]. In the N.F.T. system, the nutrient solution has a constant flow and this allows no timer to be used for the immersion pump, indispensable in substrate culture. This nutrient 
solution is pumped into the tray (usually a tube) and flows over the roots of the plants, then it drains back into the reservoir.

\subsubsection{Classification according to the way of dispensing the nutrient solution to the culture}

The drop irrigation system is perhaps the most common. It consists of a timer that controls a submersible pump allowing the nutrient solution to be distributed at the base of each plant through a drip connected to an irrigation system and it can be reused in case of excess.

The sub-irrigation system, on the other hand, consists mostly in the interception of porous or pierced pipes. In the pipes the water is pressurized so it reaches the radical root system through the soil, by capillarity. Because of the high costs it involves, this system is mostly used for valuable crops.

\subsubsection{Classification according to the presence of drained nutrient solution}

In open loop systems, the $25-30 \%$ of the nutrient solution is needed to avoid substrate salinization. The runoff is high and as a consequence the efficiency of water use is reduced, production costs are high and the risk of source contamination rises.

In closed loop systems, the drained solution is collected and re-circulated after a $\mathrm{pH}$ and nutrient concentrations adjustment. This kind of System is used to avoid environmental issues related to a high run off of nutrients in open systems. Total reuse of drainage water though is only possible when ion concentration is similar to or lower than the absorption concentration. The handling of closed systems is more complex when saline water is present, in these conditions in fact, plants may undergo high stress due to the accumulation of non-essential and potentially harmful ions.

\section{DESIGN CONCEPT}

The project we hereby propose to carry out, consists of a solar greenhouse with an integrated hydroponic cultivation system, to be occasionally adapted in order to become a receptive facility, exploiting an innovative system for cultivation lifting. The result is an architectural structure providing support to an already existing farming activity.

The greenhouse will be used as a space for the cultivating of vegetable species, but, thanks to its transformability features, new spaces assigned to different destinations of use will be generated.

In standard conditions, the greenhouse will be divided into two main modules which will house cultivations, separated by an area in which two spaces will be dedicated to supply facilities; following transformation a central space will be obtained for receptive purposes and the areas which will house the hydroponic system will have a marginal role.

The design idea foresees the creation of a simple modular facility, though featuring high technological content, based on the construction principles of prefabrication and being energetically self-sufficient, thanks to a fully integrated photovoltaic system on the roof
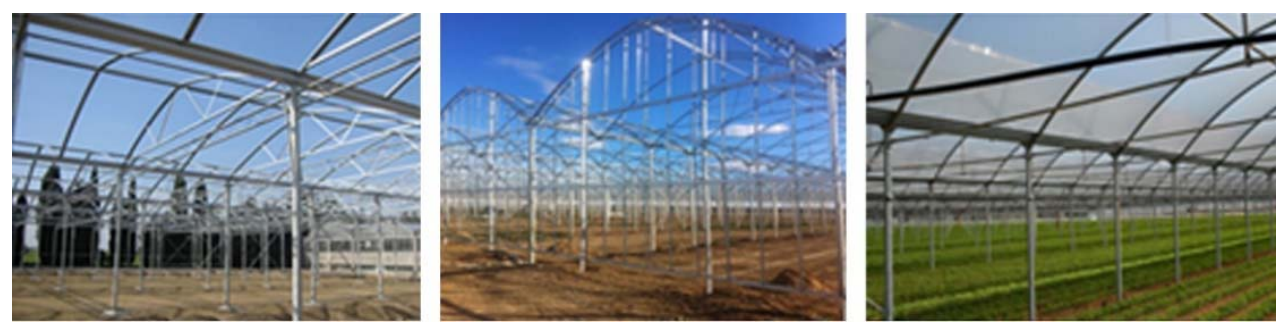

Figure 7: Galvanized steel structures images. 
which will enable the facility to cover most of its energy requirements [19], considering also the use of renewable energy sources locally available [20], [21], and the use of storage systems [22] for optimizing the use of renewable energy [23].

The supporting structure, made of modular galvanized steel, allows to better personalize shape and dimensions, according to client needs (Fig. 7). By hot-dip galvanizing we generally mean dipping iron manufacts in melted zinc, kept at an average temperature of $450^{\circ} \mathrm{C}$, which determines the coating of the steel with a thin resistant layer of zinc. Despite being very thin, this layer is impenetrable for aggressive species, and will be able to reduce zinc corrosion to a value equal to $1 / 17-1 / 18$ of the speed at which unprotected steel dissolves. This choice is dictated by the need to provide the structure with a life span of at least twenty-five years or as long as the duration of the integrated photovoltaic plant. Furthermore, it will have to bear heavy loads and overloads due to snow, water and wind as foreseen by technical regulations for buildings (Italian Ministerial Decree of January 2008).

To extend the duration of the protective coating throughout the nominal life of the facility, the carrying out of ordinary maintenance will be required before any traces of rust appear and preferably as soon as alterations in the protective coating are detected (pulverizing, cracking, damage of various nature, etc...). Extraordinary maintenance instead, will be required in the event of the conditions foreseen by UNI EN ISO 4628-3 regulations and more precisely upon the reaching of Ri3 levels of rusting ( $1 \%$ of the facility surface) or in the event of specific damage to the protective coating.

As far as coating materials are concerned, the choice made was of a type of bi-oriented rigid PVC (Fig. 8). This material will allow for the passage of short infra-red rays (heat rays) and will prevent the leaking of far infrared rays emitted by the soil (black-bodies) thus ensuring the greenhouse effect; it will furthermore be able to transmit the rays which will ensure photosynthesis in plants, however partially preventing the passage of ultraviolet rays, inhibitors of the photosynthetic process. Thanks to the special bi-orientation treatment, panels will be shockproof and hail resistant. Indeed, their resilience in traction is superior to 1200 $\mathrm{KJ}$ sqm, i.e. between two and three times more than normal PVC panels; these values will remain stable also at low temperatures (up to $-60^{\circ} \mathrm{C}$ ).

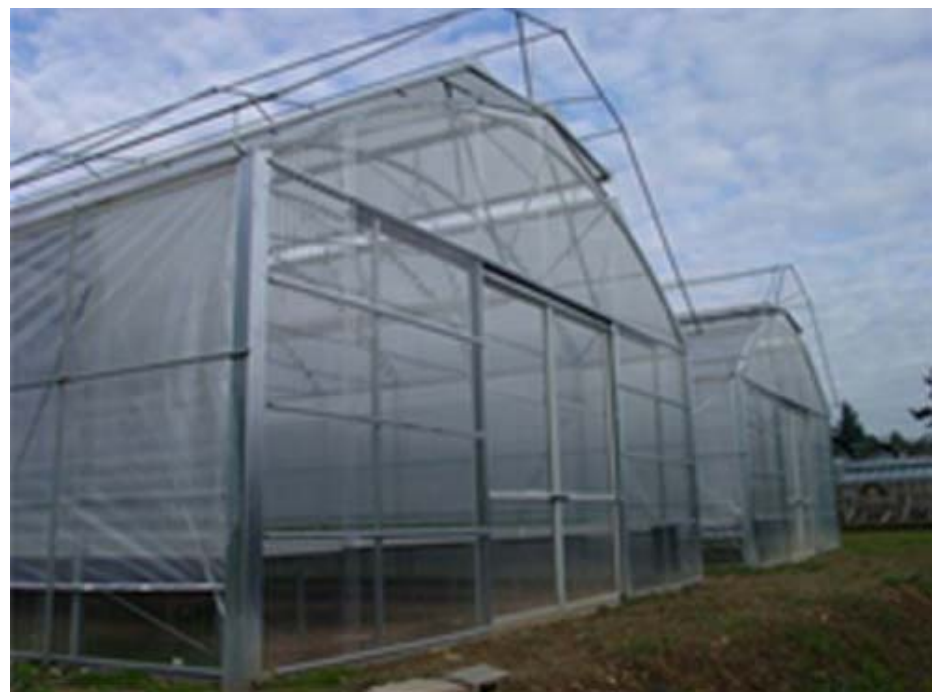

Figure 8: Greenhouse coating in PVC. 
The multi-pitch coating instead will allow for maximizing agricultural productivity, ideal for the cultivation of any kind of vegetables that normally prefer diffused lighting rather than direct [24]; alternatively, photovoltaic glass with crystalline cells can be used.

The greenhouse will extend over a surface of about $100 \mathrm{sqm}$, with a minimum height of 4 $\mathrm{m}$ and a maximum height of $6 \mathrm{~m}$, according to the frames selected for the cultivation. The pitches in the coating facing south will be tilted by $30^{\circ}$, guaranteeing maximum productiveness to the integrated photovoltaic plant, while for the remaining part openable transparent surfaces will be used, such as low-emission glass (Low-E glass), to make the environment more airy, permitting natural circulation of air and thus counteract high summer temperatures, caused by the greenhouse effect.

Concerning flooring, a floating type will be used based on a quadrangular structure which will act as a support, being completely closed by cover panels which make up the actual floor area. This system foresees prefabricated supports, made of polypropylene, a plastic material. The supports mentioned can be adjustable or fixed, and will carry out the task of allowing for the detaching of the floor from the underlying surface, starting from a minimum of $2 \mathrm{~cm}$ to a maximum of $15 \mathrm{~cm}$; this hollow space will allow for the indoor housing of power systems, which would otherwise take up a part of the main room.
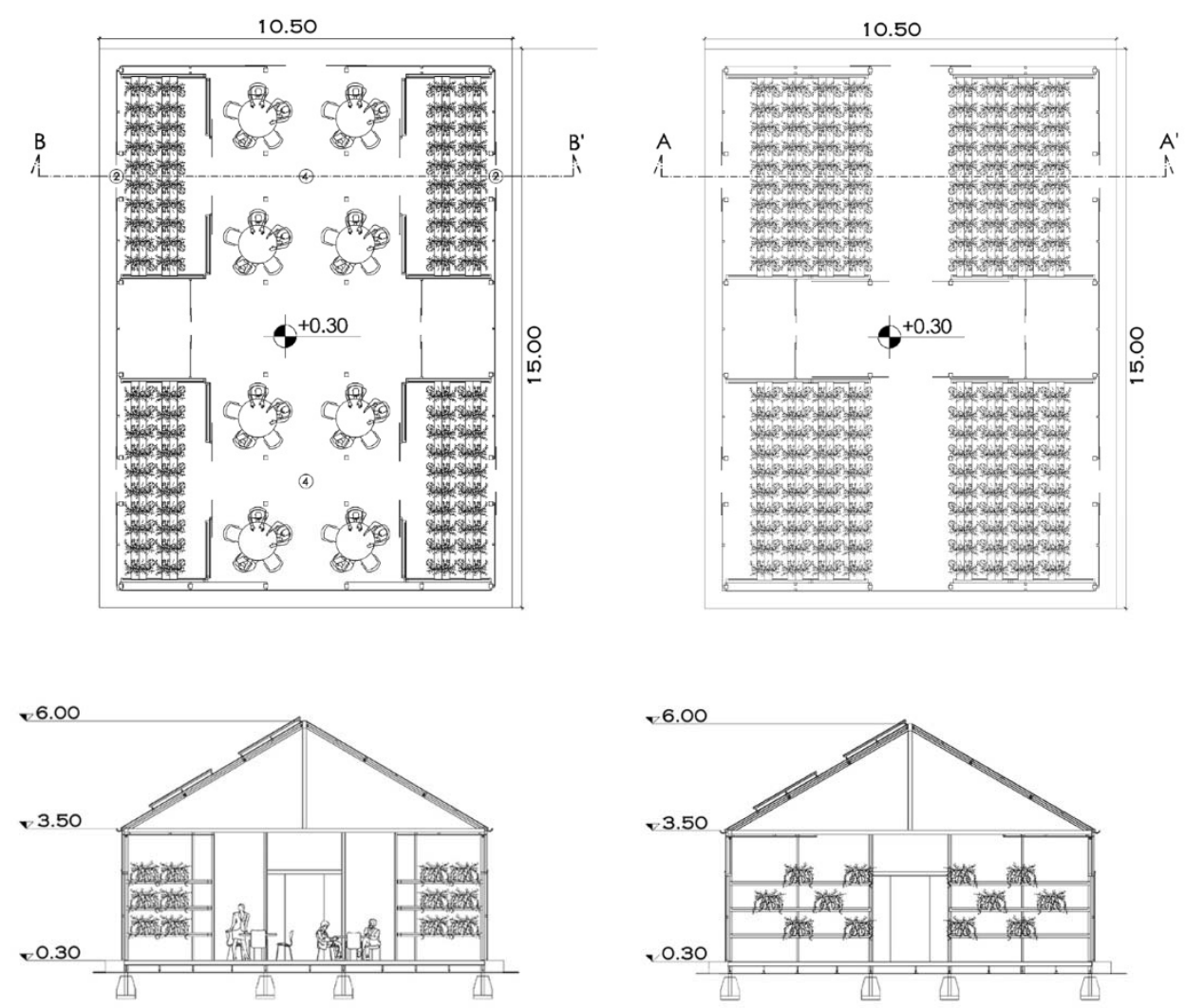

Figure 9: First project of hydroponic greenhouse in standard and transformed conditions, plants and sections. This proposal provides the horizontal movement of the cultivation slots. 
The special feature of the project, though, lies in the automated lifting system of all the cultivation frames. This technique foresees the installation of winches fuelled by electric engines directly anchored to the upper part of the greenhouse. They will lift on command, by means of steel cables, all the cultivation structures which will be positioned under the roofing. Once they have been lifted, the cultivation structures will leave space to the wide underlying room and will not be visible inside thanks to special screened panels anchored to the base of the frames. The system will therefore be perfectly integrated with the supporting structure of the greenhouse. In alternative, a similar movement system allows the horizontal sliding of the cultivation frames, freeing space in the center of the greenhouse (Figs 9-10). An efficient air-conditioning system with heat pumps will provide for the mitigation of the interior climate by regulating temperatures and humidity (Fig. 11). Modern Fan-Coils produce a forced-air flow, by means of the fan they are equipped with; active air recirculation involving the entire environment prevents the formation of stagnant areas and maintains a pleasant and uniform internal climate.

Furthermore an enthalpy heat recovery device will supply up to $1000 \mathrm{~m} 3 / \mathrm{h}$ of exchange air, meeting air hygiene standards and complying with the latest regulations. The plant will be made up of a structure in special treated paper which will allow for the crossing of flows exchanging heat energy between one another.
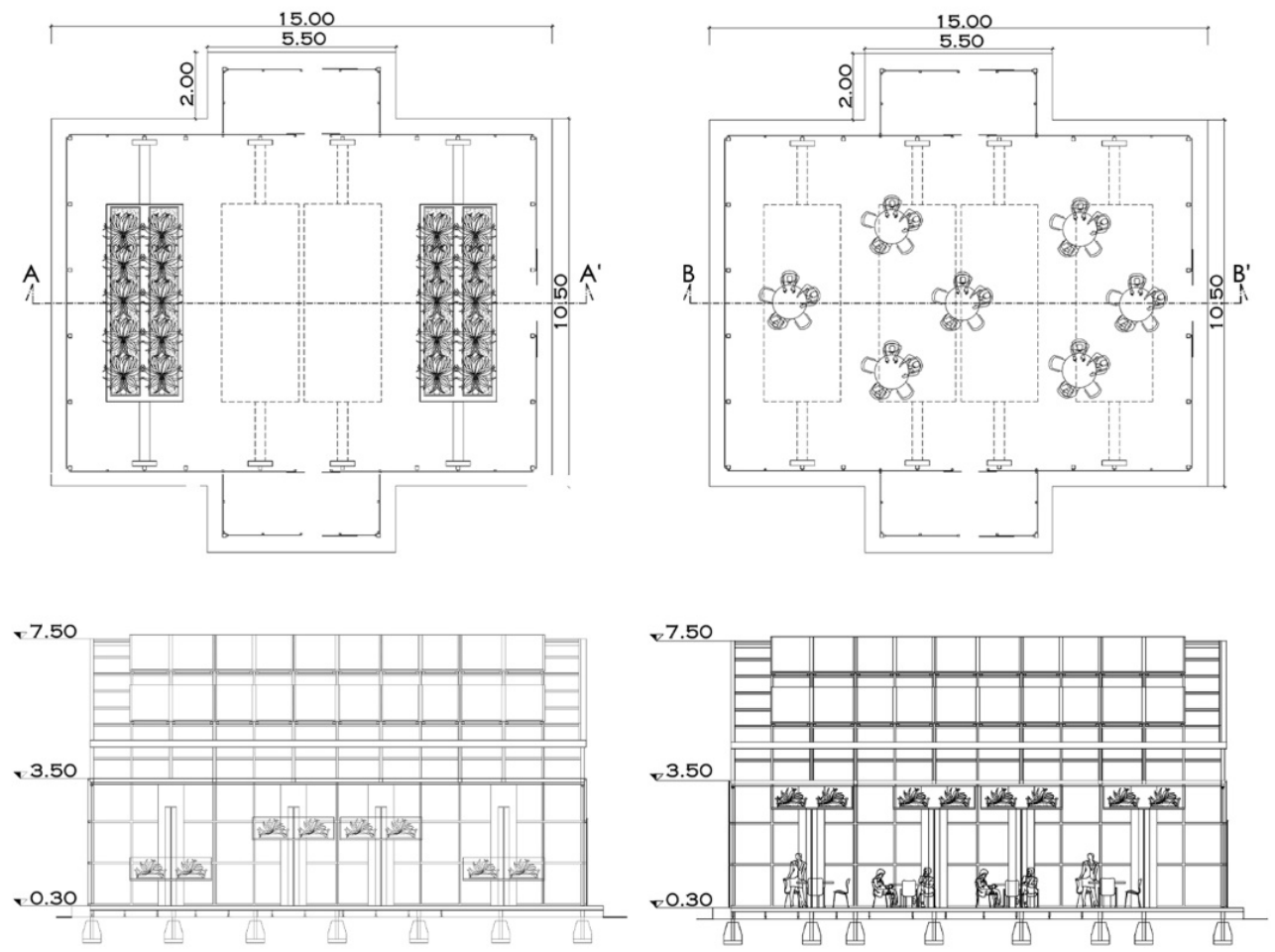

Figure 10: Second project of hydroponic greenhouse in standard and transformed conditions, plants and sections. This proposal provides the vertical movement of the cultivation slots. 

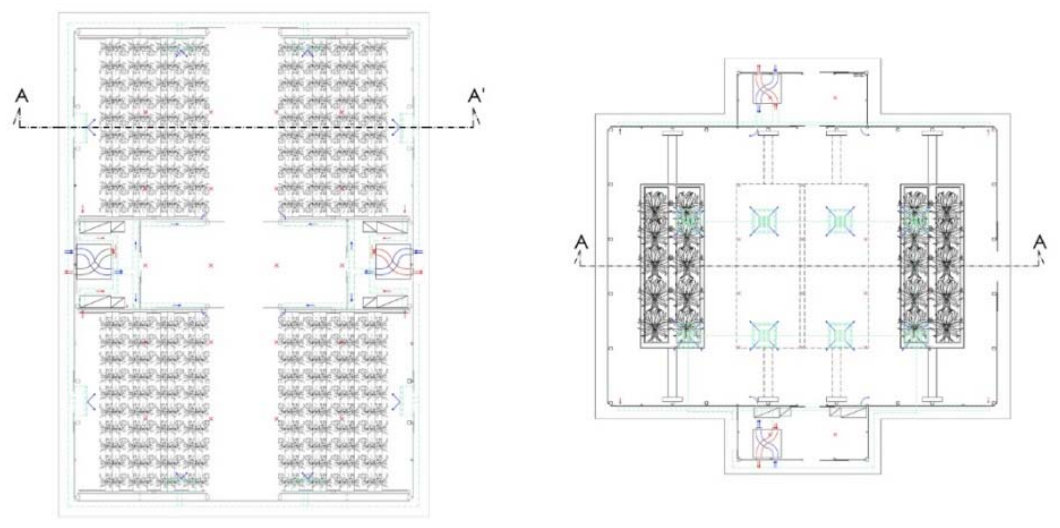

Figure 11: Plants of the two hydroponic greenhouses design proposals with indication of air-conditioning system with heat pumps.

\section{CONCLUSIONS}

The soilless cultivation has clear advantages in environmental situations where the substrate cannot make the crop grow optimally, such as rock or excessively sandy soil. Another advantageous feature lies in less water use to achieve the same result: approximately onetenth compared to the cultivation on the ground. This system is particularly useful in those environmental situations where water shortage makes it difficult or even impossible to cultivate.

Do not underestimate the environmental aspect as fertilizer use is targeted and there is no dispersion in the soil.

At the same time, the advantage in using this application is also found in economic terms, making it more fruitful to recall the structure for other uses than the standard known ones, modifying by "simple moves" the intended use, in order to attribute a multiple functional valence to the greenhouse: space for events, accommodations and agriculture. In Italy, where about $20 \%$ of the territory lays in protected area the proposed solutions may fit the cogent requirements for building construction, due to an extremely low environmental impact working together with an important increase of economic production of the soil following the basic principle of the green economy. Consequently, the proposed greenhouse solution, helping Italy to reach Europe 20-20-20 goals on renewable energy production, may help even the Italian tourist industry that is increasingly based on country B\&B and agritourism located in the most valuable zones that always are even national, regional or local protected areas.

Hydroponic greenhouses, when characterized by accurate design and architectural quality, can become an improvement not only for functional features but also for aesthetic and perceptive ones, especially in the urban environment.

A recent example of such innovative use of hydroponic greenhouses is the Ur.CA project, developed by the Centro Abita of the Faculty of Architecture of the University of Florence and financed by the Tuscany Region. The objective of the project is the requalification of unused and marginal urban areas trough a temporary, reversible and self-sufficient hydroponic greenhouse.

Therefore, the greenhouse is used not only for agricultural production but also as a multifunctional space for the advantage of citizens. 


\section{REFERENCES}

[1] Bruschi, D., Astiaso Garcia, D., Gugliermetti, F. \& Cumo, F., Characterizing the fragmentation level of Italian's National Parks due to transportation infrastructures. Transportation Research Part D: Transport and Environment, 36, pp. 18-28, 2015.

[2] Astiaso Garcia, D., Can radiant floor heating systems be used in removable glazed enclosed patios meeting thermal comfort standards? Building and Environment, 106, pp. 378-388, 2016.

[3] Cumo, F., Astiaso Garcia, D., Stefanini, V. \& Tiberi, M., Technologies and strategies to design sustainable tourist accommodations in areas of high environmental value not connected to the electricity grid. International Journal of Sustainable Development and Planning, 10(1), pp. 20-28, 2015.

[4] Bonasia, A., Lazzizera, C., Elia, A. \& Conversa, G., Nutritional, biophysical and physiological characteristics of wild rocket genotypes as affected by soilless cultivation system, salinity level of nutrient solution and growing period. Frontiers in Plant Science, 8, 2017.

[5] Arenella, V. et al., Procedure for the space certification of a controller for soilless cultivation. Proceedings of the 3rd IEEE International Workshop on Metrology for Aerospace, Metro Aero Space, pp. 359, 2016.

[6] Walters, K.J. \& Currey, C.J., Hydroponic greenhouse basil production: Comparing systems and cultivars. Hort Technology, 25(5), pp. 645-650, 2015.

[7] Natalio, F. et al., Structural analysis of Gossypium hirsutum fibers grown under greenhouse and hydroponic conditions. Journal of Structural Biology, 194(3), pp. 292-302, 2016.

[8] Astiaso Garcia, D., Cinquepalmi, F. \& Cumo, F., Air quality in Italian small harbours: A proposed assessment methodology. Rendiconti Lincei, 24(4), pp. 309-318, 2013.

[9] Cumo, F., Guidi, G., Francione, V. \& Ortore, E., A methodological proposal for monitoring atmospheric pollutants by means of satellites, CHISA 2006. Proceedings of the 17th International Congress of Chemical and Process Engineering, 2006.

[10] Astiaso Garcia, D., Di Matteo, U. \& Cumo, F., Selecting eco-friendly thermal systems for the "Vittoriale Degli Italiani" historic museum building. Sustainability, 7(9), Switzerland, pp. 12615-12633, 2015.

[11] Grewal, H.S., Maheshwari, B. \& Parks, S.E., Water and nutrient use efficiency of a low-cost hydroponic greenhouse for a cucumber crop: An Australian case study. Agricultural Water Management, 98(5), pp. 841-846, 2011.

[12] Al Shami, A., Harik, G., Alameddine, I., Bruschi, D., Astiaso Garcia, D. \& El-Fadel, M., Risk assessment of oil spills along the Mediterranean coast: A sensitivity analysis of the choice of hazard quantification. Science of the Total Environment, 574, pp. 234 245, 2017.

[13] Harik, G. et al., Implications of adopting a biodiversity-based vulnerability index versus a shoreline environmental sensitivity index on management and policy planning along coastal areas. Journal of Environmental Management, 187, pp. 187-200, 2017.

[14] Di Matteo, U., Pezzimenti, P.M. \& Astiaso Garcia, D., Methodological proposal for optimal location of emergency operation centers through multi-criteria approach. Sustainability, 8(1), Switzerland, pp. 1-12, 2016.

[15] Savvas, D. et al., Interactions between salinity and irrigation frequency in greenhouse pepper grown in closed-cycle hydroponic systems. Agricultural Water Management, 91(1-3), pp. 102-111, 2007. 
[16] Astiaso Garcia, D., Green areas management and bioengineering techniques for improving urban ecological sustainability. Sustainable Cities and Society, 30, pp. 108117, 2017.

[17] Awad, Y.M. et al., Biochar, a potential hydroponic growth substrate, enhances the nutritional status and growth of leafy vegetables. Journal of Cleaner Production, 156, pp. 581-588, 2017.

[18] Ferrarezi, R.S. \& Testezlaf, R., Performance of wick irrigation system using selfcompensating troughs with substrates for lettuce production. Journal of Plant Nutrition, 39(1), pp. 147-161, 2016.

[19] Carbonara, E., Tiberi, M. \& Astiaso Garcia, D., Analysis of energy performance improvements in Italian residential buildings. Energy Procedia, p. 855, 2015.

[20] Astiaso Garcia, D., Sangiorgio, S. \& Rosa, F., Estimating the potential biomasses energy source of forest and agricultural residues in the Cinque Terre Italian National Park. Energy Procedia, p. 674, 2016.

[21] Di Matteo, U., Nastasi, B., Albo, A. \& Astiaso Garcia, D., Energy contribution of OFMSW (Organic Fraction of Municipal Solid Waste) to energy-environmental sustainability in urban areas at small scale. Energies, 10(2), 2017.

[22] Astiaso Garcia, D., Barbanera, F., Cumo, F., Di Matteo, U. \& Nastasi, B., Expert opinion analysis on renewable hydrogen storage systems potential in Europe. Energies, 9(11), 2016.

[23] Astiaso Garcia, D., Analysis of non-economic barriers for the deployment of hydrogen technologies and infrastructures in European countries. International Journal of Hydrogen Energy, 42(10), pp. 6435-6447, 2017.

[24] Hernández-Apaolaza, L., Martín-Ortiz, D. \& Gárate, A., Response of wheat seedlings to Mn-lignosulfonate adhered to granular NPK. Journal of Plant Nutrition and Soil Science, 179(1), pp. 113-119, 2016.

[25] Bratanow, T. \& De Grande, G., Numerical analysis of normal stress in non-Newtonian boundary layer flow. Engineering Analysis, 6(2), pp. 20-25, 1985. 